\title{
"Parece que você está invadindo um espaço que não é seu": professoras de História narram experiências do início de carreira
}

"It seems you are trespassing a space that is not yours": History teachers narrate the career beginning experiences

Elison Antonio Paim*

\section{RESUMo}

$\mathrm{O}$ artigo apresenta uma retomada do diálogo com depoimentos realizados para a pesquisa de doutorado desenvolvida na Faculdade de Educação da Universidade de Campinas (Unicamp). Centro a discussão nas relações desenvolvidas entre os professores recém-graduados que chegam às escolas e aqueles que lá estão. Com base nas falas dos professores, foi possível captar elementos que vão além da ideia de formar professores - há um fazer-se professor. Nesse sentido, constitui-se um emaranhado de relações quando os professores interagem com diferentes sujeitos, como os professores da graduação, da escola, com os alunos, pais, professores e direções das escolas. A pesquisa possibilitou perceber que, ao narrar suas memórias e experiências, os depoentes tornam-se sujeitos, passam a ter novamente a capacidade de ser autores de suas práticas.

Palavras-chave: memória; experiência; fazer-se professor(a); início de carreira.

\section{Abstract}

This article presents a return to the dialogues with testimonies made for my doctoral research, developed at the Faculdade de Educação at the Universidade de Campinas (Unicamp). The discussion is centered in the relationships developed between the just-graduated teachers who have arrived at the schools and the teachers that were already there. Based on the teachers' statements it was possible to capture elements that go beyond the idea of training teachers there is a making of a teacher. In this sense, a medley of relationships is constituted when the teachers interact with different subjects, such as the Graduation professors, school teachers, students, parents and the school board. The research allowed us to realize that, when narrating their memories and experiences, witnesses became subjects, begin to have once again the ability of being authors of their practices.

Keywords: memory; experience; becoming a teacher; career beginning.

\footnotetext{
* Universidade Federal de Santa Catarina. Centro de Ciências da Educação, sala 400, Campus Universitário Trindade. 88010-970 Florianópolis - SC - Brasil. elison0406@gmail.com
} 


\section{A ORIGEM DOS FIOS}

... consolidadas as habilidades necessárias, chega-se a uma certa proficiência pedagógica, o que modela um estilo pessoal no comando da classe. Uma flexibilidade maior na gestão diária da classe permite à pessoa encarar de modo mais cômodo o exercício da profissão. A autoridade passa a ser mais natural, realista, segura e espontânea.

Antonio Bolívar ${ }^{1}$

Como bem expressou Antonio Bolívar, os professores, ao longo da carreira, vão construindo sua autonomia. Mas, como efetivamente acontece tal construção? Quais relações os professores recém-chegados à escola constroem com os que lá já estão, e também com os alunos, os pais de alunos, e a direção das escolas? Compreendendo que essa construção é social e historicamente datada, procuro, a seguir, aproximar-me dos processos de construção da autonomia pelo grupo de professores de História em início de carreira, com os quais dialogo. ${ }^{2}$

O texto ora apresentado é um fragmento da tese Memórias e experiências do fazer-se professor (a), apresentada na Faculdade de Educação da Universidade Estadual de Campinas (Unicamp). ${ }^{3}$ Como fontes de pesquisa, utilizei relatórios de estágio e de pesquisa produzidos pelos professores depoentes, materiais técnicos da universidade e vinte depoimentos orais. A seleção dos depoentes procurou expressar as múltiplas condições de trabalho, ou seja, escolas públicas municipais e estaduais e escolas privadas, bem como os diversos municípios da região Oeste de Santa Catarina, escolas de centro, de bairros e de comunidades do interior. Como ferramentas teóricas, utilizei as contribuições apresentadas em várias obras por Bakhtin, Benjamin, Thompson e Vigotski. ${ }^{4}$

Para pensar as memórias e experiências do 'fazer-se professor' ${ }^{5}$ foi necessário investigar: Como ocorreu a chegada dos novos professores às escolas? Como os professores focalizados iniciaram sua atuação profissional? Quais as relações estabelecidas com seus alunos, com os pais, a direção e os demais professores, nos primeiros tempos de trabalho? Quais as dificuldades encontradas e como as superaram, ou não? São algumas das questões que tangenciam este artigo cujo foco central é a chegada dos professores de História 
recém-graduados às escolas e suas relações com professores de História já estabelecidos.

\section{OlHANDO Algumas tessituras}

Neste espaço abordarei, inicialmente, como diferentes pesquisadores vêm tratando o que denominam 'choque de realidade', 'tempo de tensões', 'período de socialização pessoal', 'tornar-se professor', 'ritual de iniciação' ou 'formação de identidades', expressões comumente utilizadas para denominar o momento em que os estagiários fazem a passagem da universidade para a escola. Num segundo momento, trago as vozes dos companheiros de diálogo - professores de História - para que expressem como viveram esses momentos iniciais em suas carreiras.

A experiência em sala de aula desencadeia o processo de relacionamento dos conhecimentos da formação com os dados da própria prática e com os do contexto escolar. A sala de aula fornece pistas fundamentais para que o professor articule esses conhecimentos. Porém, a relação entre formação e prática dificulta a identificação de quais acontecimentos pertencem à formação e quais conhecimentos são provenientes da prática. ${ }^{6}$

Ao 'tornar-se professor', o sujeito vai adotando comportamentos de ensino em sala de aula, legitimados pela 'realidade' social, que implica interpretar os "padrões de comportamento dos alunos", bem como "conhecer as suas legítimas expectativas e ajustar a elas os comportamentos de professor". Esse movimento traduz-se "numa progressiva evolução, de uma concepção inicialmente ingênua e liberal para uma concepção mais pragmática e conservadora do desempenho da profissão". ${ }^{7}$ No mesmo sentido, apontando as mudanças, Silva ${ }^{8}$ afirma que os professores iniciantes "sentem que o medo começou a dar lugar à segurança adquirida através do trabalho com colegas, ao contentamento pela aquisição de experiência, ao desejo de afirmação como profissional, à espera de melhoria no seu desempenho e ao contentamento pela boa relação com os alunos, apesar de ter sido o campo onde percebem o maior número de dificuldades".

$\mathrm{Na}$ formação de identidades é que os professores iniciantes se firmam como profissionais; ao desenvolverem experiências e trocas, vão percebendo 
a necessidade de ceder em determinados pontos, na relação com os alunos, e assim vão se consolidando como profissionais.

No contexto de familiarização com a escola vivida, os professores iniciantes encontram muitas dificuldades, decorrentes de vários fatores. Guarnieri (1996) ressalta que a escolha equivocada da profissão leva ao fracasso do professor iniciante, e atribui tal fracasso aos seguintes fatores: "à inadequação de atitudes e às características pessoais; à falta de treinamento adequado para o desenvolvimento de habilidades necessárias ao ensino; à situação escolar permeada por relações autoritárias, burocráticas e hierárquicas; à estrutura organizativa rígida; à falta de recursos e materiais; ao isolamento; à execução de múltiplas tarefas e, ainda, à destinação de classes difíceis aos novos professores" (p.13).

A estrutura da escola, sua organização político-administrativa, interfere muito nas experiências que serão vividas pelos professores iniciantes. Assim, a organização dos tempos e espaços é fundamental para uma maior ou menor facilidade na inserção do novo professor no mundo escolar. O fato de os professores trabalharem na maior parte do tempo isolados na sala de aula com os seus alunos vai constituindo uma cultura do individualismo, em que os professores se recusam a partilhar experiências, problemas, dificuldades, e em abrir as portas da sala de aula ao controle e à colaboração de outros colegas. ${ }^{9}$

Além da estrutura político-administrativa das escolas, existe explícita ou implicitamente em seu interior uma estrutura hierárquica entre os diferentes sujeitos e saberes que nela convivem. Ao chegarem às escolas, os professores iniciantes encontram-se, muitas vezes, desarmados e pouco preparados com relação aos problemas de organização do trabalho em um grupo social complexo, com uma intrincada dinâmica de forças. Assim, "aos professores iniciantes são designados os piores alunos, aulas e matérias, que seus companheiros mais experientes tenham descartado". ${ }^{10}$

Numa perspectiva segundo a qual os professores constituem-se profissionalmente de forma relacional, ou seja, desenvolvem suas identidades por meio de múltiplos fios de "relações familiares, de classes, condições de gênero, características relativas à idade, etnia, religiosidade, cidadania e outros, cada um deles matizados de anseios, limites, rupturas e possibilidades", "cada um desses fios tem uma dimensão formadora" ${ }^{11}$ Assim, por intermédio desses fios vão sendo tecidas múltiplas teias de relações no interior da escola. ${ }^{12}$ 
$\mathrm{Na}$ trama das relações, para converter-se em professor é necessário negociar com estudantes e colegas. No entanto, essa negociação não corre de maneira previsível, pois o processo é "altamente interactivo, lleno de contradicciones, con una iteración constante entre la elección y las restricciones, un proceso en el que influen los profesores y que ellos mismos configuran". ${ }^{13}$

Esteve (1999) lembra que, assim que chegam à prática do magistério, os professores iniciantes começam uma revisão de suas atividades e ideais, para adaptá-los à “áspera e dura realidade da vida cotidiana em sala de aula”. Nos primeiros anos da prática profissional, os professores percebem que muitos dos seus ideais pedagógicos são "irrealizáveis, vistas as atuais limitações da prática” (p.43). Conforme avançam nas práticas docentes, os professores têm de enfrentar as dificuldades 'reais' do magistério; assim, entram em choque aquelas imagens idealizadas de sua profissão, as quais foram construídas durante seu período de formação inicial.

Mas nem só de problemas, dificuldades e renúncias vivem os professores em início de carreira. Existe uma série de conquistas, descobrimentos e possibilidades que vão descortinando-se conforme os professores colocam-se disponíveis para as diferentes aprendizagens, que ocorrem ao assumir os trabalhos na escola. Esse momento do fazer-se professor vem sempre como complemento das experiências vividas na formação inicial.

Nesse sentido, são importantes as contribuições de Walter Benjamin e Edward Palmer Thompson quando propõem pensarmos a sociedade por intermédio das experiências. Assim, podemos discutir a formação de professores com os professores, levando-se em consideração o que pensam, como vivem, quais experiências têm para contar, que metodologias desenvolvem, quais as relações que tecem entre teorias e práticas cotidianas, como constroem sua autonomia enquanto profissionais do ensino.

\section{Novos TeCELÕes SE PÕEM EM MOVIMENTO}

Destacarei, aqui, como essas questões aparecem nas experiências vividas pelos professores depoentes, ou seja, como os professores de História em início de carreira, nas experiências cotidianas, no seu fazer-se, dialogam ou não com os professores mais experientes. 
Inicialmente, partilho com os leitores o depoimento da professora Neiva, ${ }^{14}$ docente em uma escola considerada grande entre os pequenos municípios da região Oeste de Santa Catarina, onde boa parte delas tem um ou dois professores para cada disciplina. Seu depoimento é calcado na experiência de organização de uma feira escolar, na qual desenvolveu com seus alunos uma série de trabalhos a serem expostos, o que lhe proporcionou elogios da diretora da escola. Evidenciam-se, nesse episódio, elementos significativos das relações entre os professores com maior experiência e os que acabaram de chegar às escolas:

Quando cheguei, quando me efetivei, tinha dois professores de História no final de carreira. Eu procurei, pedi ajuda, para que me dessem ideia, para que montássemos essa feira juntos. No início beleza, disseram que sim, que iriam participar. Mas, quando era hora de participar, de fazer essa ajuda, de dar ideias... Montei toda uma sala dos 500 anos, mostrando as partes principais dos 500 anos e depois fazendo uma crítica dos dias de hoje. Disseram-me que sim, que iriam me ajudar, mas depois, quando chegou na hora de ajudar, não vi ninguém me ajudando. Esses professores, geralmente, não estão mais dispostos a ajudar. Quem ajuda mesmo são os outros. Mesmo essa professora de Geografia, a professora M., é uma professora excelente, que - meu Deus do céu! - ela ajuda sempre, ela está sempre envolvida comigo. Mais com ela do que com os professores de História. Parece que eles têm certa inveja da gente, fazer essas criatividades, fazer essas aulas diferentes. Porque a diretora chegou na sala de aula e disse assim: "Vocês viram o trabalho que a professora Neiva fez com os alunos? Vocês viram que coisa bonita, que os alunos estão aprendendo, estão fazendo coisas diferentes?”. Me parece que elas se sentem desvalorizadas porque não fizeram esse tipo de coisa. Então elas procuram não ajudar, procuram criticar. E, de vez em quando, dizem: "mas isso aqui, você poderia ter feito melhor". Mas não ajudam a gente, na hora, dizendo: "Olha, Neiva, aqui, vou te dar uma ideia disso e daquilo". Depois que aconteceu, se percebem alguma falha, dizem: "Na próxima vez, você pode fazer assim”. Mas elas não ajudam. Então é isso, a gente sente dificuldade com esses professores de História, porque pararam no tempo...

A professora Marilita narrou ${ }^{15}$ que as relações entre ela e a colega de História foram semelhantes às descritas pela professora Neiva e, em alguns aspectos, até mais difíceis. Isso porque, segundo a narradora, ela solicitou ajuda para seu início de trabalho e esta lhe foi negada. Porém, percebemos em sua narração sinais de reconhecimento de alteridade, tanto por quem 
estava chegando, como por quem já estava na escola. Podemos tecer aqui um diálogo com as reflexões de Norbert Elias, ${ }^{16}$ quando aponta as relações entre “os estabelecidos e os outsiders", ou seja, aqueles que já estão na escola sentem-se ameaçados e recebem os novos de forma muitas vezes agressiva, passando a desqualificar o trabalho dos que chegam, os de fora. Mas vejamos como ela narrou as suas experiências vividas, ao chegar para trabalhar na escola:

Você se depara com professores mais velhos ... E, muitas vezes, você se sente uma formiga. Porque ao invés de se unir a esse formigueiro você se sente uma formiga excluída. Por quê? Pelo fato de você iniciar, muitas delas acham que você tem que estar sempre submissa, porque elas sabem mais, elas estão se aposentando. Então, nós não temos direito nenhum de saber sobre um assunto a mais, ou ter uma forma diferente de trabalhar. Você é sempre contestada, pondo em dúvida o teu trabalho. Até se você precisar de um material, uma coisa, no meu caso eu não peço, vou atrás ou procuro outros professores. Única professora com que me acerto, mas, acho que é porque é minha geração, se formou um ano antes que eu, é a professora J. As demais têm um muro de Berlim, um muro americano entre nós, e que não é fácil ultrapassar, não porque eu não queira. Desde que comecei procurei ajuda, senti dificuldade, mas vi que não tinha retorno nenhum. Por exemplo, uma época fui pedir um material sobre o município, uma determinada professora me disse assim: "Vai lá na Prefeitura que eles têm!". Em momento nenhum ela disse assim: "Eu tenho, se você quer eu te empresto. Se por acaso você não quiser pegar o meu, vai lá na Prefeitura”. Não, aquela coisa bem direta: "Vai lá na Prefeitura que eles têm!”. Eu sabia que ela tinha. Foi no primeiro ano, em 1996, quando comecei a minha Graduação, a partir daquele momento eu disse: “Não, vou ter que fazer tudo sozinha!". Então não procurei mais. Tem até uma professora que passa raspando em mim, ela não me cumprimenta, a gente se ignora, finge que não existe. Então, além de você ter todo esse problema de material didático, de problema financeiro dos alunos, ainda você se depara com colegas achando que você está competindo e não achando que você vai trabalhar junto, que você vai contribuir um ao outro, ela com a experiência dela e, eu, digamos, com a minha forma nova de trabalhar, que seria diferente. Não existe isso. Aqui não existe.

Evidenciam-se, nas narrativas, elementos constituintes da racionalidade técnica, instrumental, que historicamente foi sendo implementada nas escolas: 
cada uma realiza o seu trabalho sem se vincular com as demais. Explicita-se, exatamente, o modelo de escola concebido pela modernidade capitalista, no qual predominam as relações verticalizadas, hierarquizadas entre os sujeitos, que nela convivem de maneira distanciada.

Nessa falta de relação de troca com o outro, revelam-se alguns elementos constitutivos do ser professor, que não encontra no outro a si próprio e, nesse sentido, repudia o outro, bem como, ao mesmo tempo, vai se fazendo nessa relação com o outro ao disputar espaços, tempos, saberes, atenções. Na relação com o outro, ao tentar colocar-se como diferente, como superior, como mais capacitado, escondem-se, muitas vezes, as fraquezas e as dificuldades. Portanto, se o outro pensar que sou diferente, que faço um bom trabalho, que tenho a simpatia e o respeito dos dirigentes, escondo, assim, as fraquezas e me torno alguém que precisa ser respeitado.

A professora Nanci relatou ${ }^{17}$ suas experiências de convívio com outra professora de História, no caso, a professora Gentília, também nossa depoente. Destacou que, em muitos momentos, planejaram juntas. Para ela, o que teria facilitado essa cooperação foi a proximidade de ideias e a formação inicial semelhante, vivida por ambas.

Olha, eu trabalhei com a professora Gentília, nós duas, ela se formou um ano antes que eu. Então, tínhamos a mesma postura, a mesma visão de História. A gente fechava, discutia algumas questões, algum momento até levantava os problemas, que teria que montar um plano de curso melhor, dentro da Proposta Curricular. Questionava, muitas vezes, os PCNs, até que ponto podíamos aplicar o que tem, até que ponto os PCNs não são aplicados? Tínhamos esses problemas, falávamos muito sobre isso, de tempo para sentar... Nós trocávamos material, textos, tentamos trabalhar com algumas apostilas, a apostila do neoliberalismo, nós até trabalhamos aquela da consulta popular com a $8^{\mathrm{a}}$ série ... Mas eu sentia muito, professores mais antigos que se diziam pós-graduados e, muitas vezes, não estavam nem formados ainda. E, às vezes, esse pós-graduado não contribuía em nada e, muitas vezes, atrapalhava. Uma das questões polêmicas que surgiram na escola foi quando tentamos implantar um projeto da questão dos 500 anos, tentando contrapor ao que a Rede Globo trazia na televisão, a maravilha dos 500 anos, e nós querendo trabalhar os outros 500 . E a pessoa que mais resistiu foi a diretora, que é formada em História, porque ela não admitia a gente trabalhar História nessa versão. Não aceitava de forma alguma, foi bastante polêmico. Assim, até certo deboche com quem lê dentro da escola, porque se você lê, você fala 
que está analisando conceitos de outros autores, você de certa forma é visto assim: "Você está querendo dar uma de intelectual". Você é o bom que lê e está querendo aparecer frente aos teus colegas. É mais ou menos por aí que você sente que os profissionais mais antigos, que não se atualizaram, veem os novos que estão entrando hoje na escola. E eles ganham muito bem, a gente sabe disso. São pessoas que tiveram cargos comissionados, ganham suficientemente bem para se atualizar, para ter um acervo maior de livros, e são os que menos estudam e os que mais atrapalham dentro da escola. Infelizmente, é assim.

Se por um lado, a professora Nanci viveu o momento inicial de carreira em companhia de uma colega que também enfrentava, talvez, os mesmos problemas, por outro lado, em conjunto enfrentou os problemas de resistência ao que propunha, quer da parte dos alunos, quer da parte da direção e de outros colegas. Percebemos, em sua narração, aspectos próprios da cultura escolar daquela unidade escolar na qual tanto a direção quanto colegas já estabilizados em suas carreiras rejeitaram propostas de trabalho mais questionadoras e sobrevalorizaram aqueles colegas que não se propunham à inovação e ao estudar permanente.

A professora Ângela Cechetti também narrou como foi recebida na escola. ${ }^{18}$ Relatou que inicialmente uma colega de História a acusou de estar roubando a sua vaga; no entanto, depois passou a tratá-la de forma diferente, com mais cordialidade, dialogando sobre atividades que poderiam desenvolver conjuntamente:

Até a metodologia de trabalho, a formação minha e de outros professores de História no Colégio é um pouquinho diferente. Parece que você está invadindo um espaço que não é teu. Um dia, de brincadeira, uma professora me falou assim: "Então? É tu que veio para tomar o meu lugar? Tu que veio para tomar a minha vaga?". Eu falei: “Não, eu não vim tomar tua vaga. Eu até gostaria de falar contigo sobre como vamos trabalhar. Preparar junto, conversar o conteúdo que vamos trabalhar com as turmas". Mas foi só esse primeiro contato. Depois conversamos, combinamos algumas coisas, trocamos ideias, conteúdos, formas de trabalhar. O que ela acha importante, o que eu acho importante, aquilo que diverge também. Mas, um pouquinho tem, parece, uma espécie de competição.

Percebemos, assim, que a relação inicial foi de estranhamento de ambas as partes, evidenciando como a construção do professor é relacional, em que 
o desconhecido assusta, amedronta; porém, a partir do diálogo aberto ao outro as coisas foram esclarecendo-se.

\section{ENTRELAÇANDO NOVOS FIOS}

Como percebemos, as professoras em início de carreira com as quais dialogamos apresentaram dificuldades em seus relacionamentos com os colegas de História que já estavam nas escolas. Nesse sentido, permaneceram as vivências e não as experiências vividas, tecidas de forma relacional.

Percebemos que essas professoras estavam se construindo em dinâmicas relacionais. Evidentemente são relações, muitas vezes conflituosas, a despeito de algumas parcerias. Dessa maneira, aquelas professoras iniciantes que estimularam para que os professores, os alunos e a direção entendessem por que estão fazendo determinadas atividades conseguiram maior aceitação ao seu trabalho.

Esses depoimentos constituem uma tentativa de recomposição dos sujeitos nas suas totalidades; procurei ver os fragmentos, os estilhaços das experiências nas narrativas das professoras, mas também a totalidade das relações, ao pensar a escola marcada, sobretudo, pela racionalidade instrumental. Possibilitou-me perceber, nessa relação com o outro dos depoentes, o quanto é necessário, para nós pesquisadores, respeitarmos e valorizarmos nosso outro na relação de pesquisa, fazendo que este - o depoente - se torne sujeito. Assim, "o objeto de estudo torna-se então sujeito, sujeito falante, autor, do mesmo modo que aquele que o estuda". ${ }^{19}$

As professoras ao narrar suas experiências iniciais como docentes explicitaram as tensões havidas na produção de seus saberes e práticas histórico-educacionais; deixaram marcas, que evidenciam suas resistências, em prol de outras concepções, de diálogos, pautados no respeito mútuo, nas trocas dos saberes, das experiências vividas; ousaram, muitas vezes, questionar as culturas escolares, fundamentalmente marcadas pela racionalidade técnica instrumental; buscaram pequenas brechas de relações com os outros - a despeito da rigidez, da cristalização das práticas, relativas aos tempos, aos espaços e às relações socioculturais.

As memórias dessas professoras trouxeram, além de informações, o registro de experiências vividas, transmitiram saberes que foram construindo na 
relação com os diferentes sujeitos, com os quais conviveram na Graduação em História e posteriormente a ela. Percebi, assim, que, como escreveu Sacristán, ${ }^{20}$ outra racionalidade é possível no ato de fazer educação, quando pensamos para além da racionalidade científica, ou seja, a racionalidade estética, conforme Olgária Matos. $^{21}$

Esta pesquisa entrecruzou diferentes trajetórias situadas em tempos e espaços produzidos com diferentes sujeitos, cujo objeto fundamental foi buscar memórias e experiências iniciais do fazer-se professora de História. Nessa busca procurei também a minha imagem de professor, o meu fazer, as minhas memórias e experiências, na tensão das imagens dos outros, as quais se entrecruzaram ao trazer os significados relativos à questão do ser e fazer-se professor.

Ao anunciar a minha palavra e a do outro, fui tendo contato comigo e com as experiências vividas por mim e pelos outros, ou por nós em momentos historicamente datados. Tais experiências fazem sentido quando devolvem algo a cada um de nós, que rememoramos. Desse modo, reconhecemos que os professores depoentes são autores de seus saberes, de seus trabalhos, das experiências desenvolvidas em suas aulas ou em espaços diferenciados.

Evidenciaram-se muitas tensões entre o 'eu' e o 'nós' nos diferentes espaços e nas relações vivenciadas pelos professores participantes da pesquisa, mostrando como são pessoas inteiras, com dimensões consciente e inconsciente, com sonhos, com desejos, com dúvidas, com medos, com angústias, enfim, com muitas tramas que se entretecem para além do ser professor ou professora.

\section{NOTAS}

${ }^{1}$ BOLÍVAR, Antonio (Org.). Profissão professor: o itinerário profissional e a construção da escola. Bauru (SP): Edusc, 2002. p.53.

${ }^{2}$ Com a pesquisa, procurei respostas para a seguinte questão: "Como os alunos egressos do Curso de História da Universidade do Oeste de Santa Catarina (Unoesc), campus de Chapecó, nos anos de 1998 e 1999, avaliam as experiências vivenciadas na passagem de acadêmicos para profissionais?".

${ }^{3}$ PAIM, Elison Antonio. Memórias e experiências do fazer-se professor(a) de História. Tese (Doutorado) -Faculdade de Educação, Unicamp. São Paulo, 2005.

${ }^{4}$ Algumas das obras: BAKHTIN, Mikhail (Volochinov). Marxismo e filosofia da linguagem. 10.ed. São Paulo: Hucitec; Annablume, 2002; BENJAMIN, Walter. Experiência e po- 
breza. In: Magia e técnica, arte e política. 7.ed. São Paulo: Brasiliense, 1994. p.114-119. (Obras Escolhidas, v.1); O narrador. In: Magia e técnica..., 1994, p.197-221; Infância em Berlim por volta de 1900. In: Rua de mão única. 5.ed. São Paulo: Brasiliense, 1995. p.73-142. (Obras Escolhidas, v.2); THOMPSON, Edward Palmer. A miséria da teoria: ou um planetário de erros. Rio de Janeiro: Zahar, 1981. Ver também: PAIM, Elison Antonio. Fala professor (a): o ensino de História em Chapecó. Chapecó (SC): Grifos, 1997.

${ }^{5}$ A expressão 'fazer-se professor' foi o mote da pesquisa em relação direta com a obra $A$ formação da classe operária inglesa, de Edward Palmer Thompson, em que o autor defende que há um fazer-se da classe operária. Em diálogo com a produção thompsoniana defendo a tese segundo a qual há um 'fazer-se professor' para além da ideia corrente do 'formar professores'.

${ }^{6}$ GUARNIERI, Maria Regina. Tornando-se professor: o início na carreira docente e a consolidação da profissão. Tese (Doutorado em Educação) - UFSCar. São Carlos (SP), 1996.

${ }^{7}$ CARROLO, Carlos. Formação e identidade profissional dos professores. In: ESTRELA, Maria Teresa (Org.). Viver e construir a profissão docente. Porto (Portugal): Ed. Porto, 1997. p.21-50. p.42.

${ }^{8}$ SILVA, Maria Celeste Marques da. O primeiro ano de docência: o choque com a realidade. In: ESTRELA, 1997, p.51-80. p.66.

${ }^{9}$ SARMENTO, Manuel Jacinto. A vez e a voz dos professores: contributo para o estudo da cultura organizacional da escola primária. Porto (Portugal): Ed. Porto, 1994; ALVES, Francisco Cordeiro. A (in)satisfação dos professores: estudo de opiniões dos professores do ensino secundário do distrito de Bragança. In: ESTRELA, 1997, p.81-115.

${ }^{10}$ ESTEVE, José Manuel. O mal estar docente: a sala de aula e a saúde dos professores. Bauru (SP): Edusc, 1999. p.131.

${ }^{11}$ VASCONCELOS, Geni A. Nader (Org.). Como me fiz professora. Rio de Janeiro: DP\&A, 2000. p.11.

12 JESUS, Regina de Fátima de. Sobre alguns caminhos trilhados... ou mares navegados... hoje, sou professora. In: VASCONCELOS, 2000, p.21-41.

${ }^{13}$ BULLOUGH JR., Robert V. Convertirse en profesor: la persona y la localización social de la formación del profesorado. In: GOODSON, Ivor F.; BIDDLE, Bruce J.; GOOD, Thomas L. (Org.). La enseñanza y los profesores. Barcelona: Paidós Ibérica, 2000. p.99-165. p.101.

${ }^{14}$ Depoimento oral de Neiva Bruneto Bês, abr. 2001.

${ }^{15}$ Depoimento oral de Marilita Claudia Bertolo Sagaz, 9 abr. 2001.

${ }^{16}$ ELIAS, Norbert; SCOTSON, John. Os estabelecidos e os outsiders. Rio de Janeiro: Zahar, 2000.

${ }^{17}$ Depoimento oral de Nanci Laufer Krindges, 15 maio 2001. 
${ }^{18}$ Depoimento oral de Ângela Maria de Lima Cechetti, 10 jul. 2002.

${ }^{19}$ AMORIM, Marília. O pesquisador e seu outro: Bakhtin e as Ciências Humanas. São Paulo: Musa, 2004. p.188.

${ }^{20}$ SACRISTÁN, J. Gimeno. Poderes instáveis em Educação. Porto Alegre: Artmed, 1999. Nesse livro o autor trabalhou com a possibilidade de trocarmos a racionalidade técnica manifesta na educação quando esta se arvora científica - por outra racionalidade; de acordo com ele, a educação deveria se constituir como arte e não como ciência.

${ }^{21}$ MATOS, Olgária. Vestígios: escritos de filosofia e crítica social. São Paulo: Palas Athena, 1998.

Artigo recebido em 20 de dezembro de 2012. Aprovado em 14 de abril de 2013. 